\title{
A general iterative method for quasi- nonexpansive mappings in Hilbert space
}

\author{
$M \operatorname{Tian}^{*}$ and $X$ Jin
}

* Correspondence: tianming1963@126.com College of Science, Civil Aviation University of China, Tianjin 300300, China

\begin{abstract}
Iterative algorithms have been extensively studied over the class of nonexpansive mappings in Hilbert spaces. Recall that nonexpansive mappings belong to quasinonexpansive mappings. The aim of this article is expanding the general approximation method proposed by Marino and Xu to quasi-nonexpansive mappings in Hilbert spaces.
\end{abstract}

Keywords: quasi-nonexpansive mapping, iterative analysis, variational inequality, fixed point, viscosity method

\section{Introduction}

Let $H$ be a real Hilbert space with inner product $\langle\cdot, \cdot\rangle$, and induced norm $\|\cdot\|$. A mapping $T: H \rightarrow H$ is called nonexpansive if $\|T x-T y\| \leq\|x-y\|$ for all $x, y \in H$. The set of the fixed points of $T$ is denoted by $\operatorname{Fix}(T):=\{x \in H: T x=x\}$.

Iterative theory and methods for nonlinear mappings and variational inequalities have recently been applied to solve convex minimization problems, zero point problems and many others; see, e.g., [1-9] and references therein.

The viscosity approximation method was first introduced by Moudafi [10]. Starting with an arbitrary initial $x_{0} \in H$, define a sequence $\left\{x_{n}\right\}$ generated by:

$$
x_{n+1}=\frac{\varepsilon_{n}}{1+\varepsilon_{n}} f\left(x_{n}\right)+\frac{1}{1+\varepsilon_{n}} T x_{n}, \forall n \geq 0,
$$

where $f$ is a contraction with a coefficient $\alpha \in[0,1)$ on $H$, i.e., $\|f(x)-f(y)\| \leq \alpha \| x$ $y \|$ for all $x, y \in H$, and $\left\{\varepsilon_{n}\right\}$ is a sequence in $(0,1)$ satisfying the following given conditions:

(1) $\lim _{n \rightarrow \infty} \varepsilon_{n}=0$;

(2) $\sum_{n=0}^{\infty} \varepsilon_{n}=\infty$;

(3) $\lim _{n \rightarrow \infty}\left(\frac{1}{\varepsilon_{n}}-\frac{1}{\varepsilon_{n+1}}\right)=0$.

It is proved that the sequence $\left\{x_{n}\right\}$ generated by (1.1) converges strongly to the unique solution $x^{*} \in C(C:=F i x(T))$ of the variational inequality:

$$
\left\langle(I-f) x^{*}, x-x^{*}\right\rangle \geq 0, \quad \forall x \in \operatorname{Fix}(T) .
$$

In [1], $\mathrm{Xu}$ proved that the sequence $\left\{x_{n}\right\}$ defined by the below process started with an arbitrary initial $x_{0} \in H$ :

(c) 2012 Tian and Jin; licensee Springer. This is an Open Access article distributed under the terms of the Creative Commons Attribution License (http://creativecommons.org/licenses/by/2.0), which permits unrestricted use, distribution, and reproduction in any medium, provided the original work is properly cited. 


$$
x_{n+1}=\alpha_{n} b+\left(I-\alpha_{n} A\right) T x_{n}, \quad \forall n \geq 0
$$

converges strongly to the unique solution of the minimization problem (1.3) provided the the sequence $\left\{\alpha_{n}\right\}$ satisfies certain conditions:

$$
\min _{x \in C} \frac{1}{2}\langle A x, x\rangle-\langle x, b\rangle
$$

where $C$ is the set of fixed points set of $T$ on $H$ and $b$ is a given point in $H$.

In [2], Marino and Xu combined the iterative method (1.2) with the viscosity approximation method (1.1) and considered the following general iterative method:

$$
x_{n+1}=\alpha_{n} \gamma f\left(x_{n}\right)+\left(I-\alpha_{n} A\right) T x_{n}, \forall n \geq 0 .
$$

It is proved that if the sequence $\left\{\alpha_{n}\right\}$ satisfies appropriate conditions, the sequence $\left\{x_{n}\right\}$ generated by (1.4) converges strongly to the unique solution of the variational inequality:

$$
\langle(\gamma f-A) \tilde{x}, x-\tilde{x}\rangle \leq 0, \forall x \in C,
$$

or equivalently $\tilde{x}=P_{F i x(T)}(I-A+\gamma f) \tilde{x}$, where $C$ is the fixed point set of a nonexpansive mapping $T$.

In [11], Maingé considered the viscosity approximation method (1.1), and expanded the strong convergence to quasi-nonexpansive mappings in Hilbert space. Motivated by Marino and $\mathrm{Xu}$ [2] and Maingé [11], we consider the following iterative process:

$$
\left\{\begin{array}{l}
x_{0}=x \in H \quad \text { arbitrarily chosen, } \\
x_{n+1}=\alpha_{n} \gamma f\left(x_{n}\right)+\left(I-\alpha_{n} A\right) T_{\omega} x_{n}, \quad \forall n \geq 0,
\end{array}\right.
$$

where $T_{\omega}=(1-\omega) I+\omega T$, and $T$ is a quasi-nonexpansive mapping. Under some appropriate conditions on $\omega$ and $\left\{\alpha_{n}\right\}$, we obtain strong convergence over the class of quasi-nonexpansive mappings in Hilbert spaces. Our result is more general than Maingé's [11] conclusion, and also extends the iterative method (1.4) to quasi-nonexpansive mappings.

\section{Preliminaries}

Throughout this article, we write $x_{n} \rightarrow x$ to indicate that the sequence $\left\{x_{n}\right\}$ converges weakly to $x . x_{n} \rightarrow x$ implies that the sequence $\left\{x_{n}\right\}$ converges strongly to $x$. The following lemmas are useful for our article.

The following identities are valid in a Hilbert space $H$ : for each $x, y \in H, t \in[0,1]$

(i) $\|x+y\|^{2} \leq\|x\|^{2}+2\langle y, x+y\rangle$;

(ii) $\|(1-t) x+t y\|^{2}=(1-t)\|x\|^{2}+t\|y\|^{2}-(1-t) t|| x-y \|^{2}$;

(iii) $\langle x, y\rangle=-\frac{1}{2}\|x-y\|^{2}+\frac{1}{2}\|x\|^{2}+\frac{1}{2}\|y\|^{2}$.

Lemma 2.1. [2]Let $H$ be a Hilbert space $H$. Given $x \in H, C$ is a closed convex subset of $H, f: H \rightarrow H$ is a contraction with coefficient $0<\alpha<1$, and $A$ is a strongly positive linear bounded operator with coefficient $\bar{\gamma}$. Then for $0<\gamma<\bar{\gamma} / \alpha$,

$$
\left\langle x-y_{1}(A-\gamma f) x-(A-\gamma f) y\right\rangle \geq(\bar{\gamma}-\gamma \alpha)\|x-\gamma\|^{2}, \quad \forall x, y \in H .
$$

That is, $A-\gamma f$ is strongly monotone with coefficient $\bar{\gamma}-\gamma \alpha$. 
Lemma 2.2. [2] Assume $A$ is a strongly positive linear bounded operator on a Hilbert space $H$ with coefficient $\bar{\gamma}>0$ and $0<\rho \leq\|A\|^{-1}$. Then $\|I-\rho A\| \leq 1-\rho \bar{\gamma}$.

Lemma 2.3. [11] Let $T_{\omega}:=(1-\omega) I+\omega T$, with $T$ being a quasi-nonexpansive mapping on $H, F i x(T) \neq \emptyset$, and $\omega \in(0,1]$. Then the following statements are reached:

(a1) $\operatorname{Fix}(T)=\operatorname{Fix}\left(T_{\omega}\right)$;

(a2) $T_{\omega}$ is quasi-nonexpansive;

(a3) $\left\|T_{\omega} x-q\right\|^{2} \leq\|x-q\|^{2}-\omega(1-\omega)\|T x-x\|^{2}$ for all $x \in H$ and $q \in \operatorname{Fix}(T)$;

(a4) $\left\langle x-T_{\omega} x, x-q\right\rangle \geq \frac{\omega}{2}\|x-T x\|^{2}$ for all $x \in H$ and $q \in \operatorname{Fix}(T)$.

Remark 2.4. (a4) was revised by Wongchan and Saejung [12] (Proposition 2).

Lemma 2.5. [13] Let $\left\{\Gamma_{n}\right\}$ be a sequence of real numbers that does not decrease at infinity, in the sense that there exist a subsequence $\left\{\Gamma_{n_{j}}\right\}_{j \geq 0 o f}\left\{\Gamma_{n}\right\}$ which satisfies

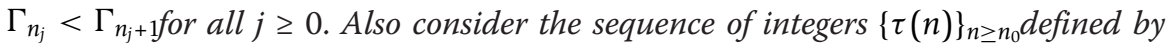

$$
\tau(n)=\max \left\{k \leq n \mid \Gamma_{k}<\Gamma_{k+1}\right\} .
$$

Then $\{\tau(n)\}_{n \geq n_{0}}$ is a nondecreasing sequence verifying $\lim _{n \rightarrow \infty} \tau(n)=\infty$ and for all $n \geq$ $n_{0}$, it holds that $\Gamma_{\tau(n)}<\Gamma_{\tau(n)+1}$ and we have

$$
\Gamma_{n} \leq \Gamma_{\tau(n)+1} .
$$

Recall the metric projection $P_{K}$ form a Hilbert space $H$ to a closed convex subset $K$ of $H$ is defined: for each $x \in H$, there exists a unique element $P_{K} x \in K$ such that

$$
\left\|x-P_{K} x\right\|:=\inf \{\|x-y\|: y \in K\} .
$$

Lemma 2.6. Let $K$ be a closed convex subset of $H$. Given $x \in H$, and $z \in K, z=P_{K} x$, if and only if there holds the inequality:

$$
\langle x-z, y-z\rangle \leq 0, \forall y \in K \text {. }
$$

Lemma 2.7. If $x^{*}$ is the solution of the variational inequality (1.5) with demi-closedness of $T$ and $\left\{y_{n}\right\} \in H$ is a bounded sequence such that $\left\|T y_{n}-y_{n}\right\| \rightarrow 0$, then

$$
\liminf _{n \rightarrow \infty}\left\langle(A-\gamma f) x^{*}, y_{n}-x^{*}\right\rangle \geq 0 .
$$

Proof. We assume that there exists a subsequence $\left\{y_{n_{j}}\right\}$ of $\left\{y_{n}\right\}$ such that $y_{n_{j}} \rightarrow \tilde{\gamma}$. From the given conditions $\left\|T y_{n}-y_{n}\right\| \rightarrow 0$ and $T: H \rightarrow H$ demi-closed, we have that any weak cluster point of $\left\{y_{n}\right\}$ belongs to the fixed point set Fix $(T)$. Hence, we conclude that $\tilde{y} \in \operatorname{Fix}(T)$, and also have that

$$
\liminf _{n \rightarrow \infty}\left\langle(A-\gamma f) x^{*}, y_{n}-x^{*}\right\rangle=\lim _{j \rightarrow \infty}\left\langle(A-\gamma f) x^{*}, y_{n_{j}}-x^{*}\right\rangle .
$$

Recalling the (1.5), we immediately obtain

$$
\liminf _{n \rightarrow \infty}\left\langle(A-\gamma f) x^{*}, y_{n}-x^{*}\right\rangle=\left\langle(A-\gamma f) x^{*}, \tilde{y}-x^{*}\right\rangle \geq 0 .
$$

This completes the proof.

\section{Main results}

Let $H$ be a real Hilbert space, let $A$ be a bounded linear operator on $H$, and let $T$ be a quasi-nonexpansive mapping on $H$, and $f$ is a contraction with coefficient $\alpha$; that is $\| f$ 
$(x)-f(y) \| \leq \alpha|| x-y||$ for all $x, y \in H$. Assume the set Fix(T) of fixed points of $T$ is nonempty and we note that $\operatorname{Fix}(T)$ is closed and convex (see [14] for more general results).

Throughout this article, we assume that $A$ is strongly positive; that is, there exist a constant $\bar{\gamma}>0$ such that $\langle A x, x\rangle \geq \bar{\gamma}\|x\|^{2}$, for all $x \in H$. Let $0<\gamma<\bar{\gamma} / \alpha$.

Theorem 3.1. Starting with an arbitrary chosen $x_{0} \in H$, let the sequence $\left\{x_{n}\right\}$ be generated by

$$
x_{n+1}=\alpha_{n} \gamma f\left(x_{n}\right)+\left(I-\alpha_{n} A\right) T_{\omega} x_{n},
$$

where the sequence $\left\{\alpha_{n}\right\} \subset(0,1)$ satisfies $\lim _{n \rightarrow \infty} \alpha_{n}=0$, and $\sum_{n=0}^{\infty} \alpha_{n}=\infty$. Also $\omega \in\left(0, \frac{1}{2}\right), T_{\omega}:=(1-\omega) I+\omega T$ with two conditions on $T$ :

(C1) $\|T x-q\| \leq\|x-q\|$ for any $x \in H$, and $q \in$ Fix(T); this means that $T$ is a quasi-nonexpansive mapping;

(C2) $T$ is demiclosed on $H$; that is: if $\left\{y_{k}\right\} \in H, y_{k} \rightarrow z$, and $(I-T) y_{k} \rightarrow 0$, then $z \in$ $\operatorname{Fix}(T)$.

Then $\left\{x_{n}\right\}$ converges strongly to the $x^{*} \in F i x(T)$ which is the unique solution of the VIP:

$$
\left\langle(\gamma f-A) x^{*}, x-x^{*}\right\rangle \leq 0, \forall x \in \operatorname{Fix}(T) .
$$

Remark 3.2. Equivalently, from the VIP (3.2), we have

$$
x^{*}=P_{F i x(T)} \circ(I-A+\gamma f) x^{*} .
$$

Proof. First we show that $\left\{x_{n}\right\}$ is bounded.

Take any $p \in \operatorname{Fix}(T)$, from Lemma 2.3 (a3), we have

$$
\begin{aligned}
\left\|x_{n+1}-p\right\| & =\left\|\alpha_{n} \gamma f\left(x_{n}\right)+\left(I-\alpha_{n} A\right) T_{\omega} x_{n}-p\right\| \\
& =\left\|\alpha_{n} \gamma\left(f\left(x_{n}\right)-f(p)\right)+\alpha_{n}(\gamma f(p)-A p)+\left(I-\alpha_{n} A\right)\left(T_{\omega} x_{n}-p\right)\right\| \\
& \leq \alpha_{n} \gamma \alpha\left\|f\left(x_{n}\right)-f(p)\right\|+\alpha_{n}\|\gamma f(p)-A p\|+\left(1-\alpha_{n} \bar{\gamma}\right)\left\|x_{n}-p\right\| \\
& \leq\left(1-\alpha_{n}(\bar{\gamma}-\gamma \alpha)\right)\left\|x_{n}-p\right\|+\alpha_{n}\|\gamma f(p)-A p\| .
\end{aligned}
$$

By induction

$$
\left\|x_{n}-p\right\| \leq \max \left\{\left\|x_{0}-p\right\|, \frac{\|\gamma f(p)-A p\|}{\bar{\gamma}-\gamma \alpha}\right\}, \quad \forall n \geq 0 .
$$

Hence $\left\{x_{n}\right\}$ is bounded, so are the $\left\{f\left(x_{n}\right)\right\}$ and $\left\{A\left(x_{n}\right)\right\}$.

Let $x^{*}=P_{F i x(T)} \mathrm{o}(I-A+\gamma f) x^{*}$ From (3.1), we have

$$
x_{n+1}-x_{n}+\alpha_{n}\left(A x_{n}-\gamma f\left(x_{n}\right)\right)=\left(I-\alpha_{n} A\right)\left(T_{\omega} x_{n}-x_{n}\right) .
$$

Since $x^{*} \in F i x(T)$, from (a4), and together with (3.5), we obtain

$$
\begin{aligned}
& \left\langle x_{n+1}-x_{n}+\alpha_{n}\left(A x_{n}-\gamma f\left(x_{n}\right)\right), x_{n}-x^{*}\right\rangle \\
& \quad=\left\langle\left(I-\alpha_{n} A\right)\left(T_{\omega} x_{n}-x_{n}\right), x_{n}-x^{*}\right\rangle \\
& \quad=\left(1-\alpha_{n}\right)\left\langle T_{\omega} x_{n}-x_{n}, x_{n}-x^{*}\right\rangle+\alpha_{n}\left\langle(I-A)\left(T_{\omega} x_{n}-x_{n}\right), x_{n}-x^{*}\right\rangle \\
& \quad \leq-\frac{\omega}{2}\left(1-\alpha_{n}\right)\left\|x_{n}-T x_{n}\right\|^{2}+\omega \alpha_{n}\left\langle(I-A)(T-I) x_{n}, x_{n}-x^{*}\right\rangle,
\end{aligned}
$$


it follows from the previous inequality that

$$
\begin{aligned}
-\left\langle x_{n}-x_{n+1}, x_{n}-x^{*}\right\rangle \leq- & \alpha_{n}\left\langle(A-\gamma f) x_{n}, x_{n}-x^{*}\right\rangle-\frac{\omega}{2}\left(1-\alpha_{n}\right)\left\|x_{n}-T x_{n}\right\|^{2} \\
& +\omega \alpha_{n}\left\langle(I-A)(T-I) x_{n}, x_{n}-x^{*}\right\rangle .
\end{aligned}
$$

From (iii), we obviously have

$$
\left\langle x_{n}-x_{n+1}, x_{n}-x^{*}\right\rangle=-\frac{1}{2}\left\|x_{n+1}-x^{*}\right\|^{2}+\frac{1}{2}\left\|x_{n}-x^{*}\right\|^{2}+\frac{1}{2}\left\|x_{n+1}-x_{n}\right\|^{2} .
$$

Set $\Gamma_{n}:=\frac{1}{2}\left\|x_{n}-x^{*}\right\|^{2}$, and combine with (3.6), it follows that

$$
\begin{gathered}
\Gamma_{n+1}-\Gamma_{n}-\frac{1}{2}\left\|x_{n+1}-x_{n}\right\|^{2} \leq- \\
-\alpha_{n}\left\langle(A-\gamma f) x_{n}, x_{n}-x^{*}\right\rangle-\frac{\omega}{2}\left(1-\alpha_{n}\right)\left\|x_{n}-T x_{n}\right\|^{2} \\
+\omega \alpha_{n}\left\langle(I-A)(T-I) x_{n}, x_{n}-x^{*}\right\rangle .
\end{gathered}
$$

Now, we calculate $\left\|x_{n+1}-x_{n}\right\|$.

From the given condition: $T_{\omega}:=(1-\omega) I+\omega T$, it is easy to deduce that $\left\|T_{\omega} x_{n}-x_{n}\right\|$ $=\omega\left\|x_{n}-T x_{n}\right\|$. Thus, it follows from (3.5) that

$$
\begin{aligned}
\left\|x_{n+1}-x_{n}\right\|^{2} & =\left\|\alpha_{n}\left(\gamma f\left(x_{n}\right)-A x_{n}\right)+\left(I-\alpha_{n} A\right)\left(T_{\omega} x_{n}-x_{n}\right)\right\|^{2} \\
& \leq 2 \alpha_{n}^{2}\left\|\gamma f\left(x_{n}\right)-A x_{n}\right\|^{2}+2\left(1-\alpha_{n} \bar{\gamma}\right)^{2}\left\|T_{\omega} x_{n}-x_{n}\right\|^{2} \\
& \leq 2 \alpha_{n}^{2}\left\|\gamma f\left(x_{n}\right)-A x_{n}\right\|^{2}+2\left(1-\alpha_{n} \bar{\gamma}\right)\left\|T_{\omega} x_{n}-x_{n}\right\|^{2} \\
& \leq 2 \alpha_{n}^{2}\left\|\gamma f\left(x_{n}\right)-A x_{n}\right\|^{2}+2 \omega^{2}\left(1-\alpha_{n} \bar{\gamma}\right)\left\|T x_{n}-x_{n}\right\|^{2} .
\end{aligned}
$$

Then from (3.8) and (3.9), we have

$$
\begin{aligned}
\Gamma_{n+1}- & \Gamma_{n}+\left[\frac{\omega}{2}\left(1-\alpha_{n}\right)-\omega^{2}\left(1-\alpha_{n} \bar{\gamma}\right)\right]\left\|x_{n}-T x_{n}\right\|^{2} \\
\leq & \alpha_{n}\left[\alpha_{n}\left\|\gamma f\left(x_{n}\right)-A x_{n}\right\|^{2}-\left\langle(A-\gamma f) x_{n}, x_{n}-x^{*}\right\rangle\right. \\
& \left.+\omega\left\langle(I-A)(T-I) x_{n}, x_{n}-x^{*}\right\rangle\right] .
\end{aligned}
$$

Finally, we prove $x_{n} \rightarrow x^{*}$. To this end, we consider two cases.

Case 1: Suppose that there exists $n_{0}$ such that $\left\{\Gamma_{n}\right\}_{n \geq n_{0}}$ is nonincreasing, it is equal to $\Gamma_{n+1} \leq \Gamma_{n}$ for all $n \geq n_{0}$. It follows that $\lim _{n \rightarrow \infty} \Gamma_{n}$ exists, so we conclude that

$$
\lim _{n \rightarrow \infty}\left(\Gamma_{n+1}-\Gamma_{n}\right)=0 .
$$

It follows from (3.10), (3.11) and the fact that $\lim _{n \rightarrow \infty} \alpha_{n}=0$, we have $\lim _{n \rightarrow \infty} \| x_{n}$ $-T x_{n} \|=0$. Again, from (3.10), we have

$$
\begin{aligned}
& -\alpha_{n}\left[\alpha_{n}\left\|\gamma f\left(x_{n}\right)-A x_{n}\right\|^{2}-\left\langle(A-\gamma f) x_{n}, x_{n}-x^{*}\right\rangle+\omega\left\langle(I-A)(T-I) x_{n}, x_{n}-x^{*}\right\rangle\right] \\
& \quad \leq \Gamma_{n}-\Gamma_{n+1} .
\end{aligned}
$$

Then, by $\sum_{n=0}^{\infty} \alpha_{n}=\infty$, we conclude that

$$
\liminf _{n \rightarrow \infty}-\left[\alpha_{n}\left\|(\gamma f-A) x_{n}\right\|^{2}-\left\langle(A-\gamma f) x_{n}, x_{n}-x^{*}\right\rangle+\omega\left\langle(I-A)(T-I) x_{n}, x_{n}-x^{*}\right\rangle\right] \leq 0 .
$$

Since $\left\{f\left(x_{n}\right)\right\}$ and $\left\{x_{n}\right\}$ are both bounded, as well as $\alpha_{n} \rightarrow 0$, and $\lim _{n \rightarrow \infty}|| x_{n}-T x_{n} \|=$ 0 , it follows from (3.13) that

$$
\liminf _{n \rightarrow \infty}\left\langle(A-\gamma f) x_{n}, x_{n}-x^{*}\right\rangle \leq 0 .
$$


From Lemma 2.1, it is obvious that

$$
\left\langle(A-\gamma f) x_{n}, x_{n}-x^{*}\right\rangle \geq\left\langle(A-\gamma f) x^{*}, x_{n}-x^{*}\right\rangle+2(\bar{\gamma}-\gamma \alpha) \Gamma_{n} .
$$

Thus, from (3.14), (3.15) and the fact that $\lim _{n \rightarrow \infty} \Gamma_{n}$ exists, we immediately obtain

$$
\begin{aligned}
& \liminf _{n \rightarrow \infty}\left[\left\langle(A-\gamma f) x^{*}, x_{n}-x^{*}\right\rangle+2(\bar{\gamma}-\gamma \alpha) \Gamma_{n}\right] \\
& \quad=2(\bar{\gamma}-\gamma \alpha) \lim _{n \rightarrow \infty} \Gamma_{n}+\liminf _{n \rightarrow \infty}\left\langle(A-\gamma f) x^{*}, x_{n}-x^{*}\right\rangle \leq 0,
\end{aligned}
$$

or equivalently

$$
2(\bar{\gamma}-\gamma \alpha) \lim _{n \rightarrow \infty} \Gamma_{n} \leq-\liminf _{n \rightarrow \infty}\left\langle(A-\gamma f) x^{*}, x_{n}-x^{*}\right\rangle .
$$

Finally, by Lemma 2.7, we have

$$
2(\bar{\gamma}-\gamma \alpha) \lim _{n \rightarrow \infty} \Gamma_{n} \leq 0,
$$

so we conclude that $\lim _{n \rightarrow \infty} \Gamma_{n}=0$, which equivalently means that $\left\{x_{n}\right\}$ converges strongly to $x^{*}$.

Case 2: Assume that there exists a subsequence $\left\{\Gamma_{n_{j}}\right\}_{j \geq 0}$ of $\left\{\Gamma_{n}\right\}_{n \geq 0}$ such that $\Gamma_{n_{j}}<\Gamma_{n_{j}+1}$ for all $j \in \mathbb{N}$. In this case, it follows from Lemma 2.5 that there exists a subsequence $\left\{\Gamma_{\tau(n)}\right\}$ of $\left\{\Gamma_{n}\right\}$ such that $\Gamma_{\tau(n)+1}>\Gamma_{\tau(n)}$, and $\{\tau(n)\}$ is defined as in Lemma 2.5 .

Invoking the (3.10) again, it follows that

$$
\begin{aligned}
& \Gamma_{\tau(n)+1}-\Gamma_{\tau(n)}+\left[\frac{\omega}{2}\left(1-\alpha_{\tau(n)}\right)-\omega^{2}\left(1-\alpha_{\tau(n)} \bar{\gamma}\right)\right]\left\|x_{\tau(n)}-T x_{\tau(n)}\right\|^{2} \\
& \leq \alpha_{\tau(n)}\left[\alpha_{\tau(n)}\left\|\gamma f\left(x_{\tau(n)}\right)-A x_{\tau(n)}\right\|^{2}-\left\langle(A-\gamma f) x_{\tau(n)}, x_{\tau(n)}-x^{*}\right\rangle\right. \\
& \left.+\omega\left\langle(I-A)(T-I) x_{\tau(n)}, x_{\tau(n)}-x^{*}\right\rangle\right] .
\end{aligned}
$$

Recalling the fact that $\Gamma_{\tau(n)+1}>\Gamma_{\tau(n)}$, we have

$$
\begin{aligned}
& {\left[\frac{\omega}{2}\left(1-\alpha_{\tau(n)}\right)-\omega^{2}\left(1-\alpha_{\tau(n)} \bar{\gamma}\right)\right]\left\|x_{\tau(n)}-T x_{\tau(n)}\right\|^{2}} \\
& \leq \alpha_{\tau(n)}\left[\alpha_{\tau(n)}\left\|\gamma f\left(x_{\tau(n)}\right)-A x_{\tau(n)}\right\|^{2}-\left\langle(A-\gamma f) x_{\tau(n)}, x_{\tau(n)}-x^{*}\right\rangle\right. \\
& \left.\quad+\omega\left\langle(I-A)(T-I) x_{\tau(n)}, x_{\tau(n)}-x^{*}\right\rangle\right] .
\end{aligned}
$$

From the preceding results, we get the boundedness of $\left\{x_{n}\right\}$ and $\alpha_{n} \rightarrow 0$, which obviously lead to

$$
\lim _{n \rightarrow \infty}\left\|x_{\tau(n)}-T x_{\tau(n)}\right\|=0
$$

Hence, combining (3.19) with (3.20), we immediately deduce that

$$
\begin{aligned}
\left\langle(A-\gamma f) x_{\tau(n)}, x_{\tau(n)}-x^{*}\right\rangle \leq & \alpha_{\tau(n)}\left\|\gamma f\left(x_{\tau(n)}\right)-A x_{\tau(n)}\right\|^{2} \\
& +\omega\left\langle(I-A)(T-I) x_{\tau(n)}, x_{\tau(n)}-x^{*}\right\rangle .
\end{aligned}
$$

Again, (3.15) and (3.21) yield

$$
\begin{aligned}
\left\langle(A-\gamma f) x^{*}, x_{\tau(n)}-x^{*}\right\rangle+2(\bar{\gamma}-\gamma \alpha) \Gamma_{\tau(n)} \leq & \alpha_{\tau(n)}\left\|\gamma f\left(x_{\tau(n)}\right)-A x_{\tau(n)}\right\|^{2} \\
& +\omega\left\langle(I-A)(T-I) x_{\tau(n)}, x_{\tau(n)}-x^{*}\right\rangle .
\end{aligned}
$$


Recall that $\lim _{n \rightarrow \infty} \alpha_{\tau(n)}=0$ and (3.20), we immediately have

$$
2(\bar{\gamma}-\gamma \alpha) \limsup _{n \rightarrow \infty} \Gamma_{\tau(n)} \leq-\liminf _{n \rightarrow \infty}\left\langle(A-\gamma f) x^{*}, x_{\tau(n)}-x^{*}\right\rangle
$$

By Lemma 2.7, we have

$$
\liminf _{n \rightarrow \infty}\left\langle(A-\gamma f) x^{*}, x_{\tau(n)}-x^{*}\right\rangle \geq 0 .
$$

Consider (3.23) again, we conclude that

$$
\limsup _{n \rightarrow \infty} \Gamma_{\tau(n)}=0,
$$

which means that $\lim _{n \rightarrow \infty} \Gamma_{\tau(n)}=0$. By Lemma 2.5, it follows that $\Gamma_{n} \leq \Gamma_{\tau(n)}$, thus, we get $\lim _{n \rightarrow \infty} \Gamma_{n}=0$, which is equivalent to $x_{n} \rightarrow x^{*}$.

Corollary 3.3. [11] Let the sequence $\left\{x_{n}\right\}$ be generated by

$$
x_{n+1}=\alpha_{n} f\left(x_{n}\right)+\left(1-\alpha_{n}\right) T_{\omega} x_{n}
$$

where the sequence $\left\{\alpha_{n}\right\} \subset(0,1)$ satisfies $\lim _{n \rightarrow \infty} \alpha_{n}=0$, and $\sum_{n=0}^{\infty} \alpha_{n}=\infty$. Also $\omega \in\left(0, \frac{1}{2}\right)$, and $T_{\omega}:=(1-\omega) I+\omega T$ with two conditions on $T$ :

(C1) $\|T x-q\| \leq\|x-q\|$ for any $x \in H$, and $q \in$ Fix(T); this means that $T$ is a quasi-nonexpansive mapping;

(C2) $T$ is demiclosed on $H$; that is: if $\left\{y_{\mathrm{k}}\right\} \in H, y_{k} \rightarrow z$, and $(I-T) y_{k} \rightarrow 0, z \in$ Fix $(T)$.

Then $\left\{x_{n}\right\}$ converges strongly to the $x^{*} \in \operatorname{Fix}(T)$ which is the unique solution of the VIP (3.27):

$$
\left\langle(I-f) x^{*}, x-x^{*}\right\rangle \geq 0, \forall x \in \operatorname{Fix}(T) .
$$

Acknowledgements

M. Tian was supported by the Fundamental Research Funds for the Central Universities (No. ZXH2011C002).

\section{Authors' contributions}

All authors read and approved the final manuscript.

\section{Competing interests}

The authors declare that they have no competing interests.

Received: 1 September 2011 Accepted: 20 February 2012 Published: 20 February 2012

\section{References}

1. Xu, HK: An iterative approach to quadratic optimizaton. J Optim Theory Appl. 116, 659-678 (2003). doi:10.1023/ A:1023073621589

2. Marino, G, Xu, HK: An general iterative method for nonexpansive mapping in Hilbert space. J Math Anal Appl. 318 , 43-52 (2006). doi:10.1016/j.jmaa.2005.05.028

3. Topics in Nonlinear Analysis and Optimization. World Education, Delhi (2011)

4. Khan, AR, Yao, JC: Convergence of composite iterative schemes for zeros ofm-accretive operators in Banach spaces. In: Ceng LC, Ansari QH (eds.) Nonlinear Anal Theory Methods Appl. 70, 1830-1840 (2009). doi:10.1016/j.na.2008.02.083

5. Khan, AR, Yao, JC: Viscosity Approximation Methods for Strongly Positive and Monotone Operators. In: Ceng LC, Ansari QH (eds.) Fixed Point Theory. 10, 35-71 (2009)

6. Yao, Y, Shahzad, N: New methods with perturbations for nonexpansive mappings in Hilbert spaces. Fixed Point Theory and Applications. 2011, 79 (2011). doi:10.1186/1687-1812-2011-79

7. Yao, Y, Shahzad, N: Strong convergence of a proximal point algorithm with general errors. Optim Lett

8. Yao, Y, Liou, YC, Chen, CP: Algorithms construction for nonexpansive mappings and inverse-strongly monotone mappings. Taiwanese J Math. 15, 1979-1998 (2011)

9. Yao, Y, Liou, YC, Chen, CP: A unified implicit algorithm for solving the triple-hierarchical constrained optimization problem. Math Comput Model. 55(3-4):1506-1515 (2012). doi:10.1016/j.mcm.2011.10.041 
10. Moudafi, A: Viscosity approximation methods for fixed-points problems. J Math Anal Appl. 241, 46-55 (2000). doi:10.1006/jmaa.1999.6615

11. Maingé, PE: The viscosity approximation process for quasi-nonexpansive mappings in Hilbert spaces. Com-put Math Appl. 59(1):74-79 (2009)

12. Wongchan, $\mathrm{K}$, Saejung, S: On the strong convergence of viscosity approximation process of quasi-nonexpansive mappings in Hilbert spaces. J Abstr Appl Anal 2011 (2011). Article ID 385843, 9

13. Maingé, PE: Strong convergence of projected subgradient methods for nonsmooth and nonstrictly convex minimization. Set-Valued Anal. 16(7-8):899-912 (2008). doi:10.1007/s11228-008-0102-z

14. Itoh, S, Takahashi, W: The common fixed point theory of singlevalued mappings and multivalued mappings. Pacific J Math. 79(2):493-508 (2008)

doi:10.1186/1029-242X-2012-38

Cite this article as: Tian and Jin: A general iterative method for quasi-nonexpansive mappings in Hilbert space. Journal of Inequalities and Applications 2012 2012:38.

\section{Submit your manuscript to a SpringerOpen ${ }^{\circ}$} journal and benefit from:

- Convenient online submission

- Rigorous peer review

- Immediate publication on acceptance

- Open access: articles freely available online

- High visibility within the field

- Retaining the copyright to your article

Submit your next manuscript at $\boldsymbol{s p r i n g e r o p e n . c o m ~}$ 